\title{
Sağlık İnanç Modeline Göre Sigara Bırakma Ölçeğinin Geliştirilmesi
}

\author{
Mehmet Ali Kurcer ${ }^{1} \odot$, Zeynep Erdogan ${ }^{2} \odot$
}

'Bülent Ecevit Üniversitesi Tıp

Fakütesi, Halk Sağlığı, Zonguldak, Türkiye

${ }^{2}$ Bülent Ecevit Üniversitesi Ahmet Erdoğan Sağlık Hizmetleri Meslek Yüksekokulu, Hemşirelik, Zonguldak, Türkiye

Mehmet Ali Kurcer, Prof. Dr. Zeynep Erdogan, Doç. Dr.
Illetişim:

Prof. Dr. Mehmet Ali Kurcer Bülent Ecevit Üniversitesi Tıp Fakütesi, Halk Sağlığı, Zonguldak, Türkiye Tel: +905336985484

E-Posta: kurcer@hotmail.com
Gönderilme Tarihi : 04 0cak 2019

Revizyon Tarihi ： 08 Mart 2019

Kabul Tarihi : : 10 Mart 2019
ÖZET

Giriş ve Amaç: Gençlerin sigaraya başlamasını önlemek ve bırakmalarını sağlamak toplumdaki sigara ile mücadelenin en etkili yoludur. Sağlık İnanç Modeli (SiM) günümüzde koruyucu sağ|ık davranışlarının açıklanmasında en sık kullanılan yöntemlerdendir. Bu çalışmanın amacı "SiM'e Göre Sigara Bırakma ÖIçeği"ni (SiM-SBÖ) geliştirerek öğrencilerin sigara bırakma konusunda davranışlarının açıklanmasını sağlamaktır.

Yöntem: Bu çalışmanın örneklemini Bülent Ecevit Üniversitesi'nde 2017-2018 eğitim öğretim döneminde eğitim gören, sigara kullanan ve kullanıp bırakmış 417 öğrenci oluşturmuştur. SiM-SBÖ'nin geliştirilmesi için oluşturulan 96 maddelik taslak ölçek konu hakkında uzman olan 12 doktorun görüşü doğrultusunda kapsam geçerlik oranı 0,80 'in altında değer alan maddeler çalışma kapsamından çıkarılarak 24 maddelik bir form elde edilmiştir. Faktör analizi sonrası; beş madde çıkarılmıştır. Böylece; öğrencilerin sigara bırakma davranışlarını sorgulayan altı alt boyut ve 19 maddeden oluşan SIM-SBÖ geliștirilmiștir. Veriler ortalama \pm standart sapma şeklinde belirtilmiş ve istatistiksel değerlendirme bilgisayar ortamında SPSS 11.5 paket programı kullanılarak tek yönlü varyans analizi (ANOVA), post-hoc LSD testi, Kaiser-Meyer-Olkin (KMO) katsayısı ve Barlett Sphericity testi, madde-toplam korelasyonu (Cronbach alfa) kullanılmıştır. Faktör yapılarını incelemek için Direct Oblimin analizi kullanılmıştır.

Bulgular: Yapı geçerliliği için açıklayıc faktör analizine bağlı olarak ölçekteki 24 maddeden beş tanesi birden fazla faktörde yer aldığı için çıkarılmış ve ölçek 19 madde olarak değerlendirmeye alınmıştır. SiM-SBÖ İç tutarlığın gösterilmesinde Cronbach's Alpha değerleri ölçeğin tamamı için Cra=0,820'dir. Alt ölçeklerin Cra değerleri 0,796-0,831 arasındadır. Toplam 171 (\%41) öğrenci sigara bırakma polikliniğine başvurmayı düşündüğünü belirtmiştir. SiM alt boyutlardan duyarlılık algısı, önem algısı, yarar algısı ve eyleme yönlendiricler puanı yüksek olan öğrencilerin sigara bırakma polikliniğe başvurmayı anlamlı düzeyde daha çok istemektedirler. Engel algısı ve öz-etkililik alt ölçekleri ile ilgili anlamlı bir fark bulunmamıştır.

Sonuç: SiM-SBÖ geçerli ve güvenilir bir ölçüm aracıdır. Bu ölçek sigara içen bireylerin bırakmalarını kolaylaştıracak etmenlerin belirlenmesinde, verilecek eğitim danıșmanlık ve tedaviler konusunda kolaylıklar sağlayacaktır.

Anahtar sözcükler: Sigara bırakma, sağlık inanç modeli, ölçek

\section{DEVELOPMENT OF THE SMOKING CESSATION SCALE ACCORDING TO HEALTH BELIEF MODEL}

\section{ABSTRACT}

Introduction and Objectives: Ensure that young people start smoking cessation is one of the most effective ways to prevent the fight against smoking in public. Today, the Health Belief Model (HBM) is one of the most common methods used to explain preventive health behaviors. The aim of this study was to develop the scale of "Smoking (essation according to the HBM" (HBM-SSC) and to explain the perceptions and behaviors of students about smoking cessation.

Materials and Methods: The sample of this study consisted of 417 students who studied, smoked and quit during the 2017-2018 academic year at Bülent Ecevit University. According to the opinion of 12 physicians who are experts on the subject of the draft scale which was created for the development of HBM-SSC, a 24-item form was obtained by subtracting the items whose content validity rate was below 0.80. After factor analysis; 5 items were removed. Thus; The scale of HBM-SSC which contains 19 items was developed. Data are expressed as mean \pm standard deviation and one-way ANOVA using SPSS 11.5 software for statistical evaluation, post hoc LSD test, Kaiser-MeyerOlkin (KMO) coefficient, Bartlett Sphericity test, item-total correlation and Cronbach's alpha were used. To examine the factor structure, Direct Oblimin rotation was used.

Results: Five items were removed from the 24 items in the scale depending on the factor analysis for construct validity. The scale which contains 19 items was taken into consideration. According to the HBM-SSC, Cronbach's Alpha value for the whole scale demonstration of internal consistency is $\mathrm{Cra}=0.820$. Cra values of the subscales were between $0.796-0.831$. A total of $171(41 \%)$ students reported that they were considering smoking cessation. Students who have high perceived benefits, perceived severity, perceived susceptibility and cue to action from HBM subscales are more likely to apply to smoking cessation outpatient clinics. There was no significant difference in the perceived barriers and self-efficacy subscales.

Conclusion: HBM-SSC is a valid and reliable measurement tool. This scale will provide ease of counseling and treatment, and ease in determining the factors that will make it easier for smokers to quit.

Keywords: Smoking cessation, health belief model, scale 
D ünyada en önemli önlenebilir ölüm nedeni olarak kabul edilen sigara, ciddi hastalık ve ölümlere yol açar. Ülkemizde yapılan bir meta-analizde sigara kullanımı prevalansı \%30,5 olarak bulunmuştur (1). Türkiye'de üniversite öğrencileriyle yapılan çalışmalarda üniversite öğrencilerinde sigara kullanımının yüzde 25 ile yüzde 60 arasında değişmektedir (2). Sigaraya başlama yaşı ortalaması 12,4'dür (3). Genç erişkinlik, sigaraya başlamanın önlenmesi gibi sağlığın korunması çalışmalarında önemli bir geçiş dönemidir (4). Sigarayı bırakma çabası, güçlü bir bağımlılık söz konusu olduğu için, gerekli desteklerin yokluğunda genellikle başarısızlıkla sonlanmaktadır. Bu konuda profesyonel yardımın, ilaç ve diğer desteklerin devreye girmesi halinde başarı şansı önemli ölçüde artmaktadır. Sigarayı bırakmak istediğini söyleyenlerin \%70 gibi yüksek olmasına rağmen, bırakma oranları düşüktür (5).

Sağlık İnanç Modeli (SiM) günümüzde koruyucu sağlık davranışlarının açıklanmasında sıklıkla kullanılmaktadır (6). Bu model, hastalıktan korunma ve tarama programlarına yetersiz katılımı açıklamak amacıyla 1950'lerin başında geliştirilmeye başlanmıştır $(7,8)$. Modeldeki temel kavram, koruyucu sağlık davranışlarının belirleyicilerinin öngörülmesidir (6). Algılanan sağlık risklerine değinen model tarama davranışlarını açıklamanın yanında hasta davranışı, hasta rolü davranışlarını ve sağlık davranışlarının gerçekleştirilmesini kolaylaştıran etmenleri de açıklamaktadır $(9,10)$. Model altı temel bileșenden oluşmaktadır. Algılanan duyarlıık; kişinin sağlığını tehdit eden hastalıkla ilgili algısıdır. Algılanan ciddiyet; tedavi kabul edilmediğinde ortaya çıkacak sonuçları içermektedir. Algılanan yarar; gerçekleştirilecek davranış sonucu, hastalığa yakalanma riskinin azalacağı ile ilgili algılanan yarardır. Algılanan engeller; önerilen davranışın gerçekleştirilmesini zorlaştırdığı düşünülen engeller ya da davranışın olası olumsuz yönleridir (6). Koruyucu sağlık davranışlarının gerçekleştirilmesini engelleyen en önemli değişken, algılanan engel ve algılanan yarar arasındaki farktır (10). Öz yeterlilik; beklenen sonuçlara ulaşmak için davranışın gerçekleştirilmesi ile ilgili kişinin kendine olan inancını, kararlılığını ve iradesini kapsamaktadır. Eyleme yönlendiriciler; davranışı tetikleyen ipuçlarını yakalamayı açıklar. İpuçları, davranışı tetikleyen mekanizma olarak kabul edilmektedir (6). Bu model, davranış değişikliği yönünde harekete geçmek için, hastalığın şiddetinin, algılanan duyarlılığın ve algılanan tehdit ile ilgili hazır bulunuşluğun önemli olduğunu belirtmektedir. Davranış, hastalığın şiddetini ya da algılanan duyarlılığı azaltmak amacıyla gerçekleştirilmektedir (11). Sigara bırakmaya yönelik müdahale araştırmalarında bu güne kadar transteoritik model, planlı davranış teorisi ve tutum-sosyal etki-etkinlik modeli gibi davranış değişim teorileri kullanılmıştır (12-14).

SiM'in sigara bırakma davranışını açıklamaya yönelik tek çalıșmaya rastlanmıştır (15). İlgili çalışmanın madde sayısının yüksekliği ve Farsça olması nedeniyle dilimize uygun ve daha kullanışlı bir ölçeğe gereksinim duyulmuştur.

\section{Amaç}

Bu çalışmanın birinci amacı SiM'e göre sigara bırakma ölçeğini geliştirmektir. Çalışmanın ikinci amacı ise; SiM'e göre öğrencilerin sigara bırakma ve tedavi arama konusundaki karşılaşılan engelleri tespit etmektir.

\section{Gereç ve Yöntem}

Bülent Ecevit Üniversitesinde 2017-2018 eğitim öğretim döneminde öğrenim gören toplam onaltı bin öğrenci vardır. Bu çalışmanın evreni, Bülent Ecevit Üniversitesi 2017-2018 döneminde öğrenim gören tüm fakültelerin 4. sınıf öğrencileridir. Tüm fakültelerden küme örnekleme yöntemiyle altı fakülte seçilmiştir. Tıp $(n=82)$, İşletme $(n=86)$, Uluslararası Ticaret $(n=78)$, Maliye $(n=76)$, Fizik Tedavi ve Rehabilitasyon ( $n=56)$, Mühendislik $(n=98)$. Çalışmanın örneklemini sigara kullanan ve kullanıp bırakmış 476 öğrenci oluşturmuştur. Bu öğrencilerden araştırmaya katılmayı kabul etmeyen uygulama sırasında okula gelmeyen 59 öğrenci çalışmadan çıkarılarak 417 öğrenci çalışmaya dâhil edilmiştir $(n=417)$. Çalışmaya katılma oranı \%87,6'dır. Verilerin toplanması sırasında Tıp Fakültesi 6. sınıf öğrencilerinden oluşan yedi kişilik bir ekip görev almıştır. Öğrencilere gerekli bilgilendirme yapıldıktan ve anketlerin başka bir amaçla kullanılmayacağı anlatıldıktan sonra anket formları verilmiştir. Öğrenciler anket formlarını kendi kendilerine doldurup teslim etmişlerdir. Anket formunun doldurulma süresi ortalama 10 dakikadır.

\section{Etik boyut}

Bu çalışma Bülent Ecevit Üniversitesi İnsan Araştırmaları Etik Kurulu'nun 337 protokol numaralı 02/04/2018 tarihli izin kararı ile yapılmıştır.

\section{Ölçek maddelerinin geliştirilmesi}

Bu çalışmada SiM'e yönelik literatür taramasında konunun teorik dayanakları, modelin alt gruplarına göre geliştirilmiş ölçekler taranmıştır. Dünyada sigara bırakma üzerine Sì ölçeği olmadığı için diğer alanlarda ki ölçekler incelenerek altı alt boyuta göre madde hazırlanma sürecine geçilmiştir. SiM'nde yer alan altı alt boyut olan önem algısı, 


\section{SIM'E GÖRE SIGARA BIRAKMA ÖLÇEĞi”' (SIM-SBÖ)}

\section{Duyarlılık algısı}

1- Eğer sigara içmeye devam edersem kanser olmaktan korkuyorum.

2- Eğer sigara içmeye devam edersem kalp hastası olmaktan korkuyorum.

3- Eğer sigara içmeye devam edersem ömrümün kısalacağından korkuyorum.

4- Eğer sigara içmeye devam edersem çevremdeki insanların sağlı̆ıına zarar vermekten endişeleniyorum.

5- Eğer sigara içmeye devam edersem çocuk sahibi olamamaktan korkuyorum.

6- Eğer sigara içmeye devam edersem çevremdeki insanlara da alıştırmaktan endişeleniyorum.

7- Vücudumda Kötü kokular diş- saç ve bıyık sararmalarından endişeleniyorum

\section{Önem algısı}

8- En yakın zaman da sigarayı bırakmak benim için çok önemlidir.

\section{Yarar algısı}

9- Eğer sigara içmeyi bırakırsam kanser olma riskim azalır.

10- Eğer sigara içmeyi bırakırsam kalp hastası olma riskim azalır.

11- Eğer sigara içmeyi bırakırsam daha uzun süre yaşayacağıma inaniyorum.

12- Eğer sigara içmeyi bırakırsam para tasarrufu sağlayacağıma inanıyorum.

13- Eğer sigara içmeyi bırakırsam diş ve diş eti hastalıklarından korunacağıma inanıyorum.

\section{Bariyer algısı}

14- Arkadaş ortamında zorluk yaşayacağımdan endişeleniyorum.

15- Bırakamayacağıma inanıyorum.

\section{Eyleme Geçiriciler}

16- Tıbbi destek alırsam bırakabileceğime inanıyorum.

17- Okul-arkadaş çevresinden uzaklaşırsam bırakabileceğime inanıyorum.

18- Ciddi bir hastalığa yakalanırsam bırakabileceğime inanıyorum.

Öz-Yeterlilik

19- Eğer gerçekten istersem sigarayı bırakabilirim.

duyarlılık algısı, bariyer algısı, yarar algısı, eyleme geçiriciler, özetkililik algısı, öz yeterlilik boyutlarına göre ölçekte kullanılabilecek ifadeler belirlenmiştir.

Boyutlar belirlendikten sonra her alt yapıya uygun madde havuzu oluşturulmuştur. Madde havuzu oluşturulurken, daha önce farklı araştırmacılar tarafından geliştirilen çeşitli konularda ki SiM ölçeklerinden yararlanılmıştır (16-20). Sonuçta SiM-SBÖ için 96 maddelik havuz oluşturulmuştur. Maddelerin oransal olarak birbirlerine eşit olup olmamasından ziyade, boyutu oluşturan özellikleri kapsama özellikleri dikkate alınmaya çalışı ııştır. Bu nedenle kapsam bakımından daha geniş bir alana sahip olan "duyarlılık" boyutu daha fazla madde ile sorgulanmıştır.

Oluşturulan 96 maddelik taslak form, uzman görüşleri alınmak üzere konu hakkında uzman olan ve çalışma konusu hakkında bilgilendirilen 12 doktorun görüşüne sunulmuştur. Uzmanlardan gelen dönütler yardımıyla taslak ölçek oluşturulmaya çalışılmıştır. Uzmanların görüşlerinin alınabilmesi için üçlü derecelendirme yöntemi kullanımıştır. Hazırlanan formda uzmanların her bir madde için "uygun", "kısmen uygun" ve "uygun değil" seçeneklerinden birini seçmeleri istenmiştir. Uzman formlarının tamamı tek bir formda birleştirilerek her bir maddenin olası seçeneklerine kaç uzman tarafından onay verildiği belirlenmiştir. Bu süreçte uzmanların vermiş olduğu görüşler doğrultusunda maddelerin kapsam geçerliği Veneziano ve Hooper (1997) tarafından geliştirilen kapsam geçerlik oranı ile belirlenmiştir (21). Maddeler için kapsam geçerlik oranı 0,80'in altında değer alan maddeler çalışma kapsamından çıkarılmıştır. Bazı maddeler ise anlaşılılığı arttırmak için düzeltilmiştir. Bu aşamadan sonra 24 maddelik bir form elde edilmiştir.

\section{Verilerin analizi}

Bu çalışmada, ölçek madde havuzunun verilerinin değerlendirilmesi amacıyla "Varimax" döndürme ile Açıklayıcı Faktör Analizi (AFA) yapılmıştır. Alt boyutlar ve ölçek bütünlüğü için güvenirlik yöntemleri ve madde analiz işlemleri yürütülmüştür. Ölçeklerin değerlendirilmesi sonucu elde edilen veriler aritmetik ortalama \pm standart sapma şeklinde belirtilmiş ve istatistiksel değerlendirme bilgisayar ortamında SPSS 11.5 paket programı kullanılarak tek yönlü varyans analizi (ANOVA), post-hoc LSD testi yapılmıştır. Çalışmada $p<0,05$ düzeyi anlamlı kabul edilmiştir.

\section{Bulgular}

Yapı geçerliliğiyle ilişkili bulgular

Açıklayııı faktör analizi (AFA)

Veriler önce maddeler arası bağıntı matrisinin faktör modeline uygunluğu açısından Kaiser-Meyer-Olkin (KMO) ve Bartlett Küresellik Testi'yle incelenmiştir. Verilerin faktör analizine uygun olması üzerine, SiM-SBÖ'nin yapı geçerliğini ve faktör yapısını incelemek amacıyla AFA yapılmıştır. Analizler yapılırken faktörlerin değişkenler üzerindeki ortak faktör varyansı, maddelerin faktör yükleri, açıklanan varyans oranları değerlendirilmiştir. Maddelerin faktör yükleri en az 0,30 olarak seçilmiştir. Faktör yapılarını 
incelemek için Direct Oblimin analizi kullanılmıştır. KaiserMeyer-Olkin (KMO) katsayısının 0,722 olması verilerin faktör analizine uygun olduğu göstermektedir. SiM-SBÖ'nin İçerik Analizi Tablo 1'de verilmiştir. Buna göre ilk altı komponent varyansın \%69,5'ini açıklamaktadır. SiM-SBÖ'nin açıklayıcı faktör analizi (AFA) matris yapısı Tablo 2'de sunulmuştur.

\begin{tabular}{|c|c|c|c|c|c|c|}
\hline & \multicolumn{3}{|c|}{ Başlangıç Eigen değerleri } & \multicolumn{3}{|c|}{ Özet toplamları } \\
\hline Faktör & $\begin{array}{c}\ddot{z} z \\
\text { değer }\end{array}$ & $\begin{array}{c}\text { Varyans } \\
\%\end{array}$ & $\begin{array}{c}\text { Kümülatif } \\
\%\end{array}$ & $\begin{array}{c}\text { Öz } \\
\text { değer }\end{array}$ & $\begin{array}{c}\text { Varyans } \\
\%\end{array}$ & $\begin{array}{c}\text { Kümülatif } \\
\%\end{array}$ \\
\hline 1 & 6,003 & 31,596 & 31,596 & 6,003 & 31,596 & 31,596 \\
\hline 2 & 2,088 & 10,992 & 42,588 & 2,088 & 10,992 & 42,588 \\
\hline 3 & 1,469 & 7,734 & 50,321 & 1,469 & 7,734 & 50,321 \\
\hline 4 & 1,268 & 6,675 & 56,997 & 1,268 & 6,675 & 56,997 \\
\hline 5 & 1,233 & 6,491 & 63,487 & 1,233 & 6,491 & 63,487 \\
\hline 6 & 1,148 & 6,044 & 69,531 & 1,148 & 6,044 & 69,531 \\
\hline
\end{tabular}

Tablo 2. SiM-SBÖ’nün açıklayıcı faktör analizi matris yapıIı

\begin{tabular}{|c|c|c|c|c|c|c|}
\hline Maddeler & $\begin{array}{c}1 \\
\text { Yarar } \\
\text { algısı }\end{array}$ & $\begin{array}{c}2 \\
\text { Eyleme } \\
\text { geçiriciler }\end{array}$ & $\begin{array}{c}3 \\
\text { Önem } \\
\text { algısı }\end{array}$ & $\begin{array}{c}4 \\
\text { Engel } \\
\text { algisı }\end{array}$ & $\begin{array}{c}5 \\
\text { Duyarlılık } \\
\text { algısı }\end{array}$ & $\begin{array}{c}6 \\
\text { Öz } \\
\text { yeterlilik }\end{array}$ \\
\hline Duyarlılık (1) & & & & & 0,555 & \\
\hline Duyarlılık (2) & & & & & 0,533 & \\
\hline Duyarlılık (3) & & & & & 0,484 & \\
\hline Duyarlık (4) & & & & & $-0,770$ & \\
\hline Duyarlılık (5) & & & & & $-0,673$ & \\
\hline Duyarlılık (6) & & & & & $-0,793$ & \\
\hline Duyarlıık (7) & & & & & 0,704 & \\
\hline Yarar algısı (7) & 0,855 & & & & & \\
\hline Yarar algısı (9) & 0,890 & & & & & \\
\hline Yarar algısı (10) & 0,417 & & & & & \\
\hline Yarar algısı (11) & 0,831 & & & & & \\
\hline Yarar algısı (12) & 0,664 & & & & & \\
\hline Önem algısı (13) & & & 0,674 & & & \\
\hline Engel algısı (14) & & & & 0,476 & & \\
\hline Engel algısı (15) & & & & 0,436 & & \\
\hline $\begin{array}{l}\text { Eyleme geçiriciler } \\
\text { (16) }\end{array}$ & & 0,798 & & & & \\
\hline $\begin{array}{l}\text { Eyleme geçiriciler } \\
\text { (17) }\end{array}$ & & 0,768 & & & & \\
\hline $\begin{array}{l}\text { Eyleme geçiriciler } \\
\text { (18) }\end{array}$ & & 0,710 & & & & \\
\hline Öz yeterlilik (19) & & & & & & 0,883 \\
\hline
\end{tabular}

Faktör analizi sonrası; ölçeğin Duyarlılık alt boyutundan"Sigara içtiğim için arkadaş çevremin daralacağından endişeleniyorum"; Engel alt boyutundan "Eğer sigarayı bırakırsam kilo almaktan korkuyorum,','Ders çalışırken dikkatimin azalacağından endişeleniyorum" ve "Sinirli- gergin olmaktan, çevremdekileri kırmaktan çekiniyorum", Eyleme geçiriciler alt boyutundan "Eğer geleceğimi güvence altına alırsam bırakabileceğime inanıyorum" olmak üzere toplam beş madde çıkarılmıştır. Böylece SIM-SBÖ 19 maddelik son şeklini almıştır. Ölçek Likert tipinde olup, 0 ile 4 arasında değerlendirilmektedir. Kesinlikle katılmıyorum" (0), "katılmıyorum" (1), "kararsızım" (2), "katılıyorum" (3), "tamamen katılıyorum" (4)" şeklinde derecelendirilmektedir. Ölçekten alınabilecek en düşük puan 0 , en yüksek puan 76 'dır.

\section{Güvenirlik analizi ile ilişkili bulgular}

Güvenirlik analizinde; maddelerin faktörlerle ve faktörlerin birbirleriyle ilişkisini belirlemek için madde ortalama puanları arasındaki farklar t-testi kullanılarak sınanmıştır. İc tutarlılığı madde-toplam korelasyonu ve Cronbach's alfa katsayısı ile hesaplanmıştır. SiM-SBÖ'nin iç tutarlığının gösterilmesinde Cronbach's alfa değerleri her madde için ve ölçeğin tamamı için hesaplanmış ve Tablo 3 'te verilmiştir. Alt boyutların Cronbach alfa değerleri 0,803 ile 0,831 arasında değiştiği ve yüksek güvenirliğe sahip olduğu saptanmıştır.

Tablo 3. SiM-SBÖ ve alt boyutlarının Cronbach's alfa katsayları

\begin{tabular}{lc} 
Alt boyutlar & Cronbach a \\
\hline Duyarlıık algısı & 0,831 \\
Yarar algısı & 0,811 \\
Önem algısı & 0,796 \\
Engel algısı & 0,810 \\
Eyleme geçiriciler & 0,830 \\
Öz yeterlilik & 0,798 \\
Toplam & 0,820
\end{tabular}

Öğrencilerin sosyodemografik ve sigara bırakma özellikleri Bu çalışmaya katılan 19-35 yaş arası 417 öğrencinin yaş ortalaması 22,7 22,56 'dır. Ortalama gelir düzeyi 609,5 $\pm 285,45$ TL'dir. Öğrencilerin günlük ortalama sigara kullanım adedi $14,9 \pm 6,85$ 'dir. Sigara kullanmaya başlama yaşı ortalaması $17,0 \pm 3,39$ olarak bulunmuştur. Öğrencilerin sigarayı bırakma deneme ortalaması $1,0 \pm 0,20$ olarak saptanmıştır. Araştırmaya katılan öğrencilere yapılan sigara bırakma konusunda bilgilendirme sonrasında 171 (\%41) öğrenci sigara bırakma polıkliniğine başvurmayı istediğini belirtmiştir. SiM-SBÖ'nin alt boyutlarına göre öğrencilerin sigara 
bırakma polikliniğe başvurmayı isteme durumları Tablo 4'de verilmiştir. Buna göre SiM alt boyutlarından duyarlılık algısı, önem algısı, yarar algısı ve eyleme yönlendiricler puanı yüksek olan öğrencilerin sigara birakma polikliniğe başvurmayı anlamlı düzeyde daha çok istemektedirler $(p<0,0001)$. Engel algısı ve öz-etkililik alt ölçekleri ile ilgili anlamlı bir fark bulunmamıştır $(p>0,05)$.

\begin{tabular}{|c|c|c|}
\hline $\begin{array}{l}\text { Sim } \\
\text { Alt ölçekleri }\end{array}$ & Polikliniğe başvurmayı & Ortalama $\pm S S$ \\
\hline \multirow[t]{2}{*}{ Duyarlılık algısı* } & İsteyen & $15,3 \pm 5,58$ \\
\hline & İstemeyen & $12,4 \pm 5,70$ \\
\hline \multirow[t]{2}{*}{ Önem algısı* } & İsteyen & $2,9 \pm 1,34$ \\
\hline & İstemeyen & $2,0 \pm 1,63$ \\
\hline \multirow[t]{2}{*}{ Yarar algısı* } & İsteyen & $15,3 \pm 5,34$ \\
\hline & İstemeyen & $13,6 \pm 5,15$ \\
\hline \multirow[t]{2}{*}{ Engel algıSI** } & İsteyen & $3,9 \pm 1,01$ \\
\hline & İstemeyen & $3,2 \pm 1,03$ \\
\hline \multirow[t]{2}{*}{ Eyleme yönlendiriciler* } & İsteyen & $7,6 \pm 2,80$ \\
\hline & İstemeyen & $5,6 \pm 2,05$ \\
\hline \multirow[t]{2}{*}{ Öz-etkililik** } & İsteyen & $3,0 \pm 1,88$ \\
\hline & İstemeyen & $3,0 \pm 1,44$ \\
\hline
\end{tabular}

\section{Tartışma}

SiM; dünyada ve ülkemizde kendi kendine meme muayenesi, osteoporoz ve diabetes mellitus gibi alanlarda sıklıkla kullanılmasına karşın, sigara bırakma konusunda nadiren kullanılmıştır $(13,14)$. Sigara bırakma konusunda SiM'in kullanılması ilk kez 1990'ların başında Galvin tarafından gündeme getirilmiştir. Ilerleyen yıllarda bu konuda önemli gelişme kaydedildiğini söylemek mümkün değildir (22).

Bu çalışmada Kaiser-Meyer-Olkin (KMO) katsayısı ve Barlett Sphericity testi ile verilerin faktör analizine uygun olduğu gösterilmiştir. Yapılan AFA ile başlangıçtaki 24 maddeden beşi çıkarılmış. Altı alt boyut içeren yapı korunarak madde sayısı 19'a düşürülmüştür. SiM-SBÖ alt boyutları ve ölçek toplam Cronbach's Alpha değeri 0,80'nin üzerinde olup, iç tutarlılık yüksektir. Yüksek güvenirlik katsayısı nedeniyle SiM-SBÖ’nin güvenle kullanılabilecek bir ölçüm aracı olduğunu göstermektedir.

SiM-SBÖ sigarayı bırakmaya yönelik yeni bir ölçek olmasına karşın SiM daha önce eğitim amacıyla denenmiş olup, bir ölçek geliştirme için denenmemiştir. ABD'de koroner arter hastası kadınlarda yapılan iki yöntemin karşılaştıııldığı çalışmada; Coping-Skills Relapse Prevention yönteminin, sigara bırakma konusunda SiM'e göre hazırlanmış eğitim ve destek tedavisinden daha etkili olmadığı bulunmuştur (23).

Sigara konusunda SiM kullanıldığı ilk ölçüm aracı Gholamreza ve ark. (2007) tarafından orijinal dili Farsça olan 77 maddelik bir ölçektir (24). Ancak bahsedilen ölçekte SiM sigara içme davranışını açıklamak için kullanırken bizim geliştirdiğimiz ölçekte SiM Sigara bırakma davranışını açıklamak amacıyla kullanılmıştır. Bu nedenle geliştirdiğimiz SiM-SBÖ sigara bırakma davranışını, SiM açısından değerlendiren ilk ve tek ölçme aracıdır.

Bu çalışmada sigarayı bırakmak isteyen öğrenciler, istemeyen öğrencilere göre SiM-SBÖ'nin algılanan duyarlılık, algılanan önem, algılanan yarar ve eyleme yönlendiriciler alt boyutlarından anlamlı düzeyde yüksek puanlar almışlardır. Engel algısı ve öz-etkililik alt boyutları bakımından sigarayı bırakmak isteyen ve istemeyen öğrenciler arasında anlamlı bir fark bulunmamıştır. Strencher ve ark.'nın (1985) çalışmasında, öz-yeterlik ve algılanan duyarlııı düzeyi yüksek olan hastaların sigarayı azaltma olasılığının da yüksek olduğu bildirilmiştir (25).

Gholamreza ve ark. (2007) İran'da yaptıkları çalışmada; SiM'e göre sigara eğitimi verilen ortaokul öğrencilerinin, eğitim verilmeyen kontrol gruplarına göre İran-SiM Sigara İçme Ölçeği'nin algılanan duyarlılık, algılanan önem, algılanan yarar alt boyutlarından anlamlı düzeyde yüksek puan aldıklarını saptamışlardır (26). Reisi ve ark.'nın (2014) İran İsfahan'da üniversite öğrencilerinde yaptığı çalışmada kendi geliştirdikleri SiM'e göre sigara içme davranış ölçeğinde sigara içenler, algılanan duyarlılık, sigara içmenin algılanan faydası ve algılanan öz-yeterlilikte, sigara içmeyenlere göre anlamlı düzeyde yüksek puan almışlardır (26). Panahi ve ark. tarafından İran Tahran'da SiM kullanılarak sigaradan korunmaya yönelik bir başka ölçek geliştirilmiştir (27). Bu ölçek yardımıyla öğrencilerin sigaradan korunmasına yönelik eğitim müdahalesi sonuçlarını değerlendirmişler ve müdahale grubunda kontrol grubuna göre algılanan ciddiyet, algılanan yarar ve öz etkililik puanlarının arttığını, algılan duyarlılık ve algılanan engeller puanlarının azaldığını bulmuşlardır.

Adı geçen çalışmalarda geliştirilen ölçekler, SiM'in sigara içme ve sigaradan korunma davranışlarını ölçerken, bu çaış̧mada geliştirilen ölçek SiM'in sigara bırakma davranışını açıklamaya yarayan bir ölçme aracıdır. 


\section{Sonuç ve Öneriler}

SiM-SBÖ; 19 maddeden ve altı alt boyuttan oluşmuş olup, sigara bırakmak isteyenler için geliştirilmiş geçerli ve güvenilir bir ölçüm aracıdır. Bu çalışmada sigarayı bırakmak isteyen öğrencilerin, istemeyen öğrencilere göre SiMSBÖ'nün algılanan duyarlılık, algılanan önem, algılanan yarar ve eyleme yönlendiriciler alt boyutlarından anlamlı düzeyde yüksek puanlar almış olmaları sigara bırakma konusunda geliştirilecek stratejiler için yararlı olacaktır.

Ayrıca sigara içen bireylerin bırakmalarını kolaylaştıracak etmenlerin belirlenmesinde, verilecek eğitim, danışmanlık

\section{Kaynaklar}

1. Özer N, Kılıçkap $M$, Tokgözoğlu L, Göksülük H, Karaaslan $D$, Kayıkçıoğlu $M$, et al. Türkiye'de sigara tüketimi verileri: Kardiyovasküler risk faktörlerine yönelik epidemiyolojik çalışmaların sistematik derleme, meta-analiz ve meta-regresyonu. Turk Kardiyol Dern Ars 2018;46:602-12. [CrossRef]

2. Onurlubaş E, Yıldız E, Yıldız S. Factors Affecting Cigarette Consumption of University Students: An Application on Trakya University Students. The Journal of International Scientific Researches 2017;2:83-92. [CrossRef]

3. Agu CF, Weaver S, Abel WD, Rae T, Oshi SN, Whitehorne-Smith P, et al. Are Adolescents likely to Start Smoking Early if Their Parents are Smokers? A Study of Jamaican High School Students. The Asian Pacific Journal of Cancer Prevention 2018;19:25-31. [CrossRef]

4. Villanti AC, Niaura RS, Abrams D, Mermelstein R. Preventing Smoking Progression in Young Adults: the Concept of Prevescalation. Prev Sci 2019;20:377-84. [CrossRef]

5. Rosenstock L, Cullen MR, Brodkin C, Redlich C. Textbook of Clinical Occupational and Environmental Medicine, 2nd ed. Philadelphia: WB Saunders Co.; 2004.

6. Janz NK, Champion VL, Strecher VJ. The Health Belief Model. In: Glanz K, Rimer BK, Lewis FM, editors. Health Behavior and Health Education, 3rd edition. San Fransisco: Jossey- Boss; 2002. pp.45-66.

7. Hochbaum GM. Public Participation in Medical Screening Programs: Sociopsyhologicial Study. PHS publication no. 572. Washington DC: Government Printing Office; 1958; p.36.

8. Nahcivan ÖN, Seçginli S. Meme Kanserinde Erken Tanıya Yönelik Tutum ve Davranışlar; Bir Rehber Olarak Sağlık İnanç Modelinin Kullanımı. CÜ Hemşirelik Yüksek Okulu Derg 2003;7:33-37. https://pdfs.semanticscholar.org/31b9/ c6c914a1452b6e19ad55d152fe69bd52aa56.pdf

9. Grubbs LM, Tabano M. Use of Sunscreen in Health Care Professionals: The Health Belief Model. Cancer Nurs 2000;23:164-7. [CrossRef]

10. Baltaş Z. Sağlık Psikolojisi. Halk Sağlığında Davranış Bilimleri. İstanbul: Remzi Kitabevi; 2000.

11. Mullen PD, Hersey JC, Iverson DC. Health Behavior Models Compared. Soc Sci Med 1987;24:973-81. [CrossRef]

12. De Vries $H$, Mudde AN. Predicting stage transitions for smoking cessation applying the attitude-social influence-efficacy model. Psychology Health 1998:13:369-85. [CrossRef]

13. DiClemente CC, Prochaska JO, Fairhurst SK, Velicer WF, Velasquez MM, Rossi JS. The Process of Smoking Cessation: An Analysis of Precontemplation, Contemplation, and Preparation Stages of Change. J Consult Clin Psychol 1991;59:295-304. [CrossRef] ve tedaviler konusunda kolaylıklar sağlayacaktır. Ayrıca bu ölçek bireylerin ya da toplulukların sigara bırakma yaklaşımlarına yönelik yapılacak araştırmalarda kullanılabilir.

\section{Çıkar çatışması}

Yazarların bu araştırma bağlamında açıklaması gereken herhangi bir çıkar çatışması bulunmamaktadır.

Finansal destek

Bu çalışma için herhangi bir kurumdan finansal destek alınmamıştır.

\section{Yazar katkıları}

Konsept: M. A. K Tasarım: M. A. K, Z. E, Kontrol: M. A. K, Z. E Veri toplama: M. A. K, Z. E Analiz: M. A. K, Z. E Kaynak toplama: M. A. K Yazım: M. A. K, Z. E
14. Norman P, Conner M, Bell R. The theory of planned behavior and smoking cessation. Health Psychol 1999;18:89-94. [CrossRef]

12. Weinstein ND. Testing Four Competing Theories of Health Protective Behavior. Health Psychol 1993;12:324-33. [CrossRef]

13. Karayurt Ö. Champion Sağlık İnanç Modeli Ölçeği'nin Türkiye için uyarlanması ve kendi kendine meme muayenesi uygulama sıklığını etkileyen faktörlerin incelenmesi; Ege Üniversitesi Sağlık Bilimleri Enstitüsü, Cerrahi Hastalıklar Hemşireliği Anabilim Dalı Programı Doktora Tezi, İzmir 2003.

14. Kır E. Diyabetli Hastaların Sağlık İnançlarının Bakımlarına Olan Etkilerinin İncelenmesi. Abant İzzet Baysal Üniversitesi Sağlık Bilimleri Enstitüsü, Hemşirelik Anabilim Dalı Programı Yüksek Lisans Tezi, Bolu 2003.

15. Panahi R Javanmardi E, Ramezankhani A, Osmani F, Ahmadi A, Niknami S. Psychometric properties of the scale on the related factors to smoking prevention among students of Shahid Beheshti University of Medical Sciences based on Health Belief Model. Journal of Health in the Field 2018;6:11-6. http://journals.sbmu.ac.ir/en-jhf/ article/view/23239/16038

16. Kılıç D, Erici B. Osteoporoz Sağlık İnanç Ölçeği, Osteoporoz Öz Etkililik/ Yeterlilik Ölçeği ve Osteoporoz Bilgi Testi'nin Geçerlik ve Güvenirliği. Atatürk Üniv Hemşirelik Yüksekokulu Derg 2004;7:1-15. https://toad.halileksi.net/sites/default/files/pdf/osteoporoz-saglikinanc-olcegi-toad_0.pdf

17. Sunmaz D. Ebeveyn Sağlık İnanç Ölçeğinin Türkiye'deki Geçerlik ve Güvenilirlik Çalışması. Dokuz Eylül Üniversitesi Sağlık Bilimleri Enstitüsü, Çocuk Sağlığı ve Hastalıkları Hemşireliği, Yüksek Lisans Tezi 2003.

18. Gökdoğan F, Akıncı F. Bolu'da Yaşayan Diyabetlilerin Sağlık ve Hastalıklarını Algılamaları ile Uygulamaları. C Ü Hemşirelik Yüksekokulu Derg 2001;5:10-7. http://eskidergi.cumhuriyet.edu.tr/makale/580.pdf

19. Seçginli S, Nahcivan ÖN. Reliability and Validity of the Breast Cancer Screening Belief Scale Among Turkish Women. Cancer Nurs 2004;27:287-94. [CrossRef]

20. Dündar PE, Özmen D, Öztürk B, Haspolat G, Akyıldız F, Çoban S, Çakıroğlu G. The knowledge and attitudes of breast self-examination and mammography in a group of women in a rural area in western Turkey. BMC Cancer 2006 6:43-56. [CrossRef]

21. Veneziano L, Hooper J. A method for quantifying content validity of health-related questionnaires. Am J Health Behav 1997:21:67-70.

22. Galvin KT. A Critical review of the health belief model in relation to cigarette smoking behaviour. J Clin Nurs 1992:1;13-8. [CrossRef]

23. Schmitz JM, Spiga R, Rhoades HM, Fuentes F, Grabowski J. Smoking cessation in women with cardiac risk: A comparative study of two theoretically based therapies. Nicotine Tob Res 1999;1:87-94. [CrossRef] 
24. Sharifirad G, Hazavei MM, Hasanzadeh A, Daneshamouz A. The effect of health education based on health belief model on preventive actions of smoking in grade one, middle school students. Arak Med Univ J 2007;10:79-86. http://jams.arakmu.ac.ir/ article-1-52-en.pdf

25. Strencher VJ, Becker MH, Kirscht JP, Eraker SA, Graham-Tomasi RP. Psychosocial aspects of changes in cigarette-smoking behavior. Patient Educ Couns 1985;7:249-62. [CrossRef]
26. Reisi M, Javadzade HS, Shahnazi H, Sharifirad GA, Charkazi A, Moodi $M$. Factors affecting cigarette smoking based on health-belief model structures in pre-university students in Isfahan, Iran. J Educ Health Promot 2014;3:23. [CrossRef]

27. Panahi R, Ramezankhani A, Tavousi M, Niknami S. Adding Health Literacy to the Health Belief Model: Effectiveness of an Educational Intervention on Smoking Preventive Behaviors Among University Students. Iran Red Crescent Med J 2018;20:e13773. [CrossRef] 